\title{
A Comparison of Tackified, Miniemulsion Core-Shell Acrylic Latex Films with Corresponding Particle-Blend Films: Structure-Property Relationships
}

\author{
Elisabetta Canetta ${ }^{1}$, Jeanne Marchal ${ }^{2}$, Chun-Hong Lei ${ }^{1, *}$, Fanny Deplace, ${ }^{2}$ Alexander M. \\ König $^{3}$, Costantino Creton ${ }^{2}$, Keltoum Ouzineb ${ }^{4}$, Joseph L. Keddie ${ }^{1, \dagger}$ \\ ${ }^{I}$ Department of Physics, Faculty of Engineering and Physical Sciences, University of Surrey, \\ Guildford, Surrey GU2 7XH, UK \\ ${ }^{2}$ Laboratoire de Physico-Chimie des Polymères et Milieux Dispersès, E.S.P.C.I., Paris, France \\ ${ }^{3}$ Institute of Physical Chemistry, Clausthal University of Technology, Arnold-Sommerfeld-Str. \\ 4, D-38678 Clausthal-Zellerfeld, Germany \\ ${ }^{4}$ Cytec Surface Specialities, Anderlecht Str. 33, B-1620 Drogenbos, Belgium
}

\begin{abstract}
Tackifying resins (TR) are often added to pressure-sensitive adhesive films to increase the peel strength and adhesion energy. In waterborne adhesives, the TR is dispersed in water using surfactants and then blended with colloidal polymers in water (i.e. latex). In such waterborne systems, there are problems with the colloidal stability and the ease of coating (coatability) of the particle blends, and the films are often hydrophilic and subject to water uptake. Here, an alternative method of making waterborne, tackified adhesives is demonstrated. The TR is incorporated within the core of colloidal polymer particles via miniemulsion polymerisation. Atomic force microscopy combined with force spectroscopy analysis reveals there is heterogeneity in the distribution of the TR in films made from particle blends and also in films made from miniemulsion polymers. Two populations, corresponding to TR-rich and acrylic-rich components, were identified through analysis of the AFM force-
\end{abstract}

\footnotetext{
"Present address: Department of Physics, University of Hull, Hull UK

Corresponding author. E-mail: j.keddie@surrey.ac.uk
} 
displacement curves. The nano-scale maximum adhesion force and adhesion energy were found to be higher in a miniemulsion film containing $12 \mathrm{wt} . \%$ tackifying resin in comparison to an equivalent blended film. The macro-scale tack and viscoelasticity are interpreted by consideration of the nano-scale structure and properties. The incorporation of tackifying resin through a miniemulsion polymerisation process not only offers clear benefits in the processing of the adhesive, but it leads to enhanced adhesion properties.

\section{Introduction}

Pressure-sensitive-adhesives (PSAs) are inherently-tacky materials that adhere to a substrate upon the application of light pressure. ${ }^{1,2}$ The development of waterborne (wb) PSAs synthesized via radical emulsion polymerization processes ${ }^{3}$ has been driven by requirements to reduce the emission of volatile organic compounds during processing., ${ }^{4,5}$ Waterborne polymer colloids, i.e. latexes, offer an environmentally-friendly alternative, and therefore wb-PSA technology has been increasingly studied, as demonstrated in a recent review of the subject. ${ }^{6}$ However, wb-PSAs made from latex dispersions suffer from two key limitations.

The first limitation is they tend to display low adhesion energies on non-polar, low surfaceenergy substrates, thus ruling out their suitability for the important application of polyolefinbonding. As pointed out by Tobing and Klein, ${ }^{7}$ the crosslinked network structure in a PSA film cast from a polymer solution differs from the network obtained from crosslinked gel particles in a latex. A second limitation is that wb-PSA films are usually more water-sensitive than solvent-cast films. ${ }^{8,9}$ The wb films can become cloudy after exposure to moisture, because of light scattering from water pockets, ${ }^{10}$ precluding their use in applications for clear labels and decals, where transparency is essential. 
To increase the peel force and tack strength of PSAs, it is common practice to incorporate a so-called "tackifier" or tackifying resin (TR) into PSA formulations. ${ }^{11,12,13,14}$ TRs are bulky, low-molecular-weight molecules with a glass transition above room temperature, such as $n$-butyl ester of abietic acid ${ }^{15}$ or pentaerythritol rosin ester derived from abietic acid. ${ }^{16}$ TR can be incorporated into a PSA by dissolving it in a common solvent along with the polymer. (In waterborne PSA formulations, the TR resin is conventionally dispersed in water using appropriate surfactants and then blended with a latex dispersion.) For solvent-cast tackified PSAs, there are numerous reports in the literature about the miscibility between tackifiers and polymers and the resulting phase morphology. ${ }^{15,17,18,19}$ Furthermore, the influence of solvent-cast TRs on the mechanical properties of PSAs at both the macroscopic scale $^{20,21}$ and the nano-scale 15,18,19,22,23,24 has been investigated. Force-distance spectroscopy using an atomic force microscope (AFM) with $\mathrm{X}$-modulation ${ }^{1922}$ has been particularly powerful in nano-scale measurements of tackified adhesives.

In comparison to the solvent-cast materials, waterborne tackified PSAs have been much less studied. Tobing and Klein ${ }^{25}$ elucidated the effects of TR on the viscoelasticity and the chain entanglement network of waterborne PSAs. Mallégol et al. found that the addition of TR to an acrylic PSA latex led to better particle coalescence, because the tackifier acted as a compatibilizer between the acrylic and the serum phase. ${ }^{26}$ In rubber formulations, a TR is used to dilute the entanglement network structure and to reduce the elastic modulus in the plateau region. ${ }^{13}$ In acrylic polymers, its primary role is to increase the viscoelastic dissipative properties (loss tangent) at room temperature. ${ }^{2,25,26}$

Further research is especially required in tackified wb systems, because the processing of blends of latex and TR is a source of numerous problems. Water-dispersed TR contains a substantial amount of poorly-characterized surfactants and dispersants, which can affect the colloidal stability and the coatability of the latex into which it is blended. The 
surfactants typically accumulate at the surface of wb PSAs ${ }^{27,28}$ and have been implicated in the reduction of peel and shear strengths of PSAs. ${ }^{29,30,31}$ Such additives can also raise the hydrophilicity and tendency to whiten under moisture exposure. ${ }^{\text {Error! Bookmark not defined. }}$ Additionally, the distribution of the colloidal polymer and TR resin in the final film is not very well-controlled. The flocculation of like particles will increase the heterogeneity of the PSA, with an expected negative impact on the mechanical performance. Numerous studies have also revealed that the structure of tackified PSAs evolves over time, ${ }^{17,18,26}$ with aging leading to pronounced changes in mechanical properties. ${ }^{18}$ Finally, miscible TR resins can encourage particle coalescence at the surface of waterborne PSA films during drying, resulting in the creation of a "skin layer" that traps water within the film. ${ }^{26}$ For these various reasons, an alternative approach to blending TR resins and acrylic copolymers has been sought, and herein we propose a new strategy.

Figure 1 compares a conventional approach to making waterborne, tackified PSAs and our new approach. ${ }^{32}$ We incorporate the TR resin into individual latex particles through a twostage polymerization process comprising a miniemulsion polymerisation stage (in which the TR is incorporated) followed by a conventional emulsion polymerization stage to create a shell. The TR is therefore encapsulated within the latex particles. Miniemulsion polymerization is the favored wb process when highly-hydrophobic compounds, such as a TR, need to be encapsulated or copolymerized within a polymer particle. The polymerization takes place in sub- $\mu \mathrm{m}$ monomer droplets, each acting as a "nano-reactor," as the mass transport through the aqueous phase is limited. ${ }^{33,34}$ Anticipated advantages of this "one-particle" approach, in contrast to colloidal particle blends, include a reduction in the hydrophilicity and tendency to water whiten, increased colloidal stability and coatability, being less subject to ageing effects owing to the tackifier encapsulation, and better incorporation at the nanometer scale, leading to a more optimum molecular network structure. 
(a)

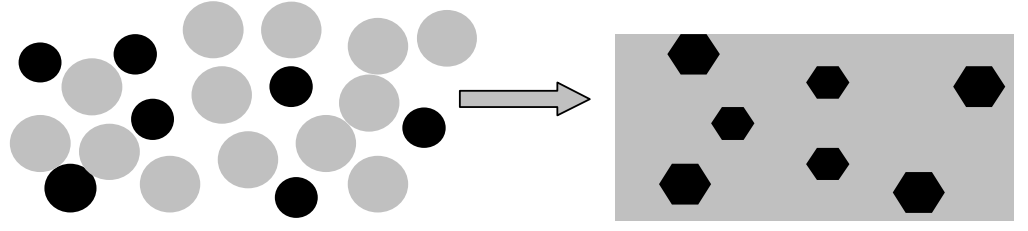

(b)

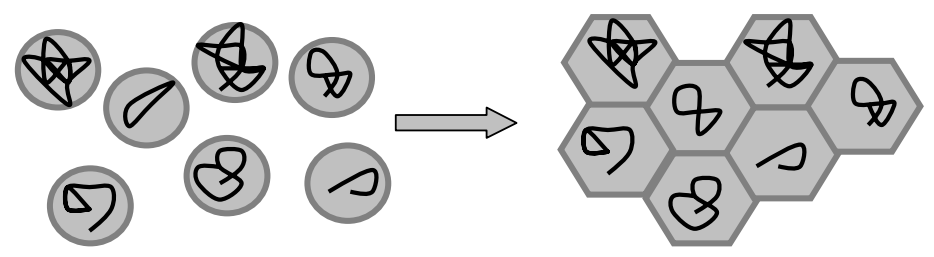

Figure 1. Comparison of two approaches to creating a composite film and the resulting film morphologies. Tackifier is represented as a minority phase (in black) and acrylic is the majority phase (in gray). (a) In a conventional approach, film formation from a blend of the two types of particles leads to a continuous majority phase (acrylic) in which the minority phase (tackifier) is dispersed. (b) In our new approach, the tackifier is encapsulated within a coreshell particle. The shells (dark gray) create the walls of a honeycomb structure upon film formation.

In the current work, the core-shell particles were designed to create PSA films with increased peel force when debonded from low-energy surfaces. The tackified particle core material has a lower glass transition temperature $\left(T_{\mathrm{g}}\right)$ and is more viscous compared to the shell. The core is thus designed to be highly viscoelastic and energy-dissipative in order to increase adhesion on non-polar substrates. The shell is designed to balance the viscoelastic liquid character of the core by reducing the film's creep, so that the PSA has adequate shear resistance; it is lightly crosslinked to raise the stiffness and elasticity.

In this paper, the structure and adhesive properties of PSAs in which the TR has been added by the conventional route of particle blending are compared with the new "one-particle" 
approach in which TR and acrylic are mixed at nanometer length scales within the individual particles by miniemulsion polymerisation. Measurements are made at the nano-scale using AFM techniques and are compared with macroscopic measurements. Although AFM phase images can provide a map of nano-scale variations in viscoelasticity across a surface, ${ }^{35,36}$ the information is qualitative and is subject to artefacts, especially for soft materials such as PSAs. ${ }^{37,38}$ Recently, maps of PSA latex surfaces, obtained via AFM noise analysis, have provided semi-quantitative information about the mechanical properties as a function of the nano-scale position. ${ }^{39}$ In other work, ${ }^{15}$ AFM force-displacement measurements have been employed to determine the viscoelastic characteristics of tackified PSAs in relation to the position on a heterogeneous surface. Here, AFM force-displacement measurements are used to create a quantitative map of the elastic and adhesive characteristics of tackified PSA surfaces.

\section{Materials and Methods}

\section{Materials}

The core of the latex particles was composed of a random copolymer of 2-ethyl hexyl acrylate, 2-EHA $\left(T_{\mathrm{g}}=-50^{\circ} \mathrm{C}\right)$, ethyl acrylate $\left(T_{\mathrm{g}}=-24^{\circ} \mathrm{C}\right)$, methyl methacrylate $\left(T_{\mathrm{g}}=105^{\circ} \mathrm{C}\right)$, acrylic acid $\left(T_{\mathrm{g}}=106^{\circ} \mathrm{C}\right)$ and styrene $\left(T_{\mathrm{g}}=100^{\circ} \mathrm{C}\right)$ as the main monomers. ${ }^{40}$ The monomers were used as received. The $T_{\mathrm{g}}$ of the core copolymer is predicted to be $-50^{\circ} \mathrm{C}$ using the Fox equation. The shell of the tackified PSA latex was made from a random copolymer of 2-EHA, butyl acrylate $\left(T_{\mathrm{g}}=-54{ }^{\circ} \mathrm{C}\right),{ }^{40}$ and styrene as the main monomers. The $T_{\mathrm{g}}$ of this copolymer is predicted to be $-45.5{ }^{\circ} \mathrm{C}$. The stability of latex particles was controlled through a mixture of anionic surfactants (2 wt.\% of the total monomer charge).

A commercial hydrocarbon tackifying resin (Piccotac 1095-N, Eastman Chemical, USA) was used in the miniemulsion polymerization. Its softening temperature is $94{ }^{\circ} \mathrm{C}$, and its glass transition temperature is $44{ }^{\circ} \mathrm{C}$, according to differential scanning calorimetry at 20 ${ }^{\circ} \mathrm{C} / \mathrm{min}$. The weight-average molecular weight $\left(M_{\mathrm{w}}\right)$ was $1700 \mathrm{~g} \mathrm{~mol}^{-1}$, and the polydispersity, 
$M_{\mathrm{w}} / M_{\mathrm{n}}$, was 2.1 . This low $M_{\mathrm{w}}$ increases its miscibility with the acrylic copolymer. To prepare waterborne blends of particles, a resin of very similar composition, suspended as particles in water (Tacolyn 1070, Eastman Chemical, USA) at a concentration of 55 wt.\%, was used.

\section{ME Polymerization Procedure}

Two-stage tackified core-shell PSA latexes were prepared from in situ tackified latexes synthesized by miniemulsion polymerization. Homogenized pre-emulsions were polymerized under a semi-continuous process during the first stage to generate the particle cores (Fig.2). This polymerization was followed by a second stage in which a classical pre-emulsion was added under starved semi-continuous conditions to create the shell.

The monomer pre-emulsions were prepared by dissolving anionic surfactants in deionized water, and dissolving the Piccotac 1095-N TR resin in the monomer phase, containing stearyl methacrylate to act as co-stabilizer. The monomer and aqueous solutions were mixed with a mechanical agitator for a few minutes. The resulting pre-emulsion was subjected to a high intensity mixer (Dr Hielsch sonifier, UP400S) for five minutes. This mechanical shearing breaks the oil phase into sub- $\mu \mathrm{m}$ droplets. The resulting homogenized pre-emulsion was then polymerized $24 \mathrm{~h}$ later using ammonium persulfate, a water-soluble free radical initiator. 

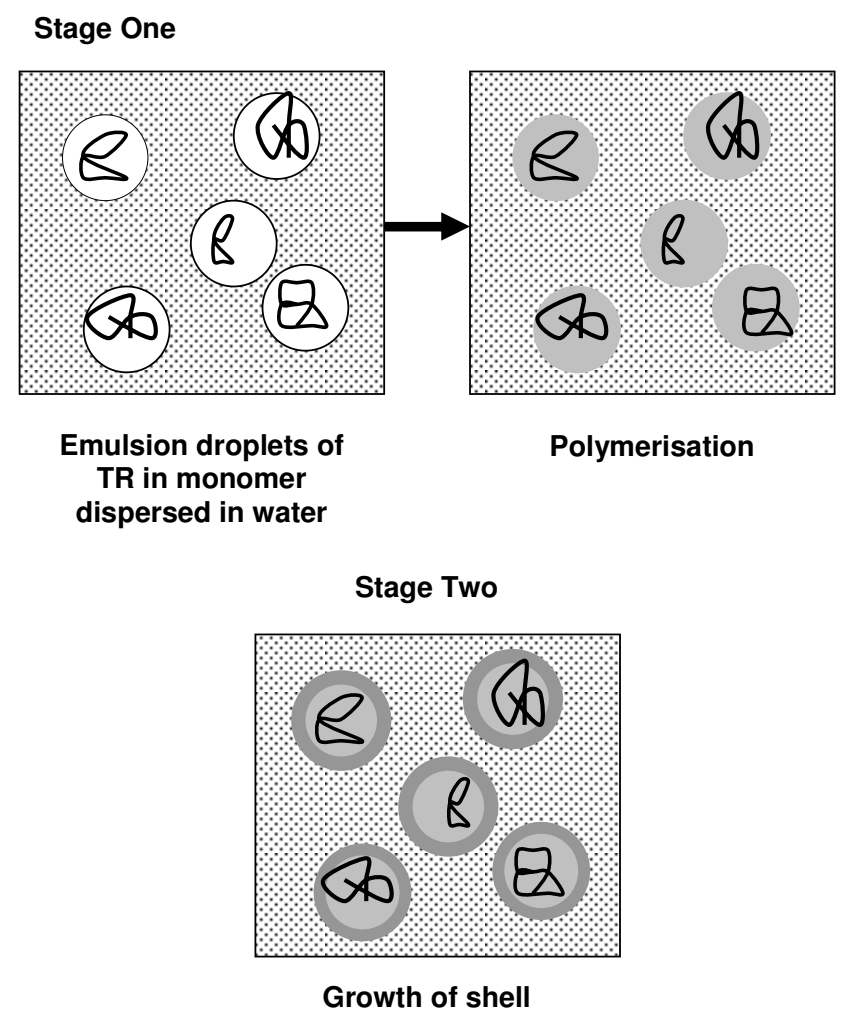

Figure 2. Schematic illustration of the miniemulsion polymerisation process. In Stage One, the tackifier (black lines) is dissolved in the monomer, and the solution is emulsified in water. The emulsion droplets are polymerised to make particles. In Stage Two, a second polymerisation is used to grow a shell around the particles.

Two different tackified miniemulsion (ME) latexes were studied: (1) a one-stage particle with 4 wt./wt\% Piccotac TR in the core (called "ME-4", where ME denotes miniemulsion and the number represents the TR content) and no shell, and (2) a two-stage particle with a $12 \mathrm{wt} / \mathrm{wt}$ \% tackified core (called "ME-12") and a core/shell volume ratio of 70/30. The TR concentration is expressed as wt. $\%$ of the monomer weight in the core. One latex was made without the addition of any TR resin (ME-0). The characteristics of the three latexes are summarized in Table1. 
Published in Langmuir (2009) 25(18): pp 11021-11031

Table 1. Core-shell miniemulsion latex characteristics

\begin{tabular}{cccc}
\hline Code & wt. \% Piccotac & Particle size (nm) $)^{\dagger}$ & Solids content (wt. \%) \\
\hline ME-0 & 0 & 216 & 52.7 \\
ME-4 & 4 & 164 & 47.37 \\
ME-12 & 12 & 217 & 52.4 \\
Mean particle size was measured with dynamic light scattering. \\
\multicolumn{4}{l}{} \\
Solids content was measured in gravimetric experiments.
\end{tabular}

\section{Film Formation}

Experiments were designed to compare the nanostructure and the nano-mechanical properties of the ME tackified latex films (as in Fig. 1b) with those of films made from blends of the latex with TR (as in Fig. 1a). Blends of the dispersions were prepared by stirring the Tacolyn 1070 TR into the pure acrylic latex (ME-0) and allowing to equilibrate for $24 \mathrm{~h}$. Films cast from the ME-12 latex were compared with blends of ME-0 plus 12 wt.\% TR and with ME-4 plus 8 wt.\% TR. Thus the total TR content was fixed but the preparation conditions were varied.

Films for AFM experiments were cast onto polypropylene sheets $(30 \mathrm{~cm} \times 20 \mathrm{~cm}$ in area) using a $10 \mu \mathrm{m}$ hand-held spiral bar coater. The films were dried at $110{ }^{\circ} \mathrm{C}$ for $3 \mathrm{~min}$. under static air. The thickness of the dried films is estimated to be $5 \mu \mathrm{m} .1 \mathrm{~cm} \times 1 \mathrm{~cm}$ pieces were cut from the cast PSA (or TR) films and mounted on the AFM sample holder. Samples were analysed within $24 \mathrm{~h}$ after casting. Prior to AFM analysis, the film surfaces were rinsed with deionised water to remove the excess surfactant.

\section{AFM Imaging and Force Spectroscopy Mapping}

The nanostructure of the PSA films was determined by using a commercial AFM instrument (NTEGRA, NT-MDT, Moscow, Russia) in intermittent contact mode, and nanomechanical properties were obtained with the same instrument using force spectroscopy ${ }^{41}$ (FS) 
to create maps of nanomechanical properties. All the AFM experiments were performed in air at room temperature.

For imaging, silicon cantilevers (ATEC-NC, Nanosensors, Switzerland) with a nominal spring constant of $k=45 \mathrm{~N} / \mathrm{m}$ and a resonance frequency of $330 \mathrm{~Hz}$ were used. An ultrasharp silicon tip with a radius of curvature of $c a .10 \mathrm{~nm}$ was micro-fabricated on the cantilever. Height and phase images $(256 \times 256$ pixels $)$ were collected using a scan speed of $1.56 \mathrm{~Hz}$. A lateral resolution of $30 \mathrm{~nm}$ is estimated for all the captured images.

The set-point amplitude $A_{\mathrm{sp}}$ (i.e. amplitude of the oscillation when the tip is in contact with the surface sample) was kept just below the free amplitude $A_{0}$, which was typically $295 \mathrm{~nm}$, in order to image the PSA surface in "soft-tapping" conditions to minimize indentation. ${ }^{37,38}$ In the phase images presented here, dark regions represent greater energy dissipation between the tip and cantilever, which results from a greater viscous component of the viscoelasticity. ${ }^{35}$ Brighter regions are attributed to a surface with a lower viscous component and greater elasticity.

For nanomechanical mapping experiments, $\mathrm{Si}_{3} \mathrm{~N}_{4}$ cantilevers (CSG10, NT-MDT, Moscow, Russia) with a nominal spring constant of $0.1 \mathrm{~N} / \mathrm{m}$, a nominal resonant frequency of $20 \mathrm{kHz}$, and a radius of curvature of $c a .10 \mathrm{~nm}$ were used in contact mode. FS curves were recorded at 400 points in a square grid of $20 \times 20$ points across a $2 \mu \mathrm{m} \times 2 \mu \mathrm{m}$ area of the sample surface. In each of the 400 FS measurements, the AFM tip was brought into contact with the surface with an average normal force of $5 \mathrm{nN}$, and then the surface was lowered away from the tip at a speed of $0.45 \mu \mathrm{m} / \mathrm{s}$. FS data, composed of a trace curve (corresponding to the indentation cycle) and a retrace curve (corresponding to the retraction cycle), were recorded at each point. The true distance, $d$, between the sample and the AFM tip was calculated from the FS data by subtracting the deflection of the cantilever, $z$, from the height values that corresponded to the measured piezoelectric displacement, $z_{\text {piezo }}$ : 
$d=z_{\text {piezo }}-z$

Nano-mechanical properties

During the data analysis, commercial software (Gigasoft ProEssentials v3 Package) was used to display the $F$ - $d$ curves. Each of the 400 curves in a data set was individually shifted to remove its offset. Then, the maximum adhesive force of the tip to surface $\left(F_{\max }\right)$, the maximum distance of deformation of the sample $\left(d_{\max }\right)$, and the adhesion energy $\left(W_{\mathrm{adh}}\right)$ were calculated from the $F$ - $d$ curves by using dedicated program written with Borland Delphi 7.0 software. The adhesion energy, $W_{\text {adh }}$, was obtained from the area under the $F$ - $d$ curve.

The Young's (elastic) modulus $E$ at the sample surface was also determined from analysis of the $F$-d indentation curves using an approach described elsewhere ${ }^{42}$ and derived from a Hertzian model of elastic contacts developed by Sneddon. ${ }^{43}$ The force $F$ required by a rigid cone with a half-opening angle $\alpha\left(11^{\circ}\right.$ in this work) to indent a distance $\delta$ into a surface is given by:

$$
F=\frac{2 \tan (\alpha) E \delta^{2}}{\pi\left(1-v^{2}\right)}
$$

where a soft polymer can be treated as an isotropic media with a Poisson's ratio of $v=0.5$. The contribution of the adhesive force to the contact area between the tip and the surface is neglected in this calculation, and so $E$ will be referred to as an effective modulus, $E_{\mathrm{eff}}$, as done previously. $^{44}$

\section{Macro-scale measurements}

For tack experiments, a small amount of latex was deposited at one end of a precleaned microscope glass slide and spread with a doctor blade having a gap of 300 or $400 \mu \mathrm{m}$. The films were allowed to dry in air at room temperature and ambient humidity for about ten $\mathrm{h}$. At the end of this first drying step, the layers were transparent. They were then dried in an oven 
at $110{ }^{\circ} \mathrm{C}$ for $5 \mathrm{~min}$ at atmospheric pressure. The resulting films had thicknesses of approximately $100 \mu \mathrm{m}$.

For the rheological experiments, the latex was deposited in silicone moulds. The wet latex was allowed to dry in air over a period of about ten days at room temperature and ambient humidity. The samples were then dried at $110{ }^{\circ} \mathrm{C}$ for $5 \mathrm{~min}$. at atmospheric pressure. The resulting films had thicknesses of approximately $800 \mu \mathrm{m}$.

\section{Probe tack experiments}

Probe tack experiments were performed at room temperature $\left(22{ }^{\circ} \mathrm{C}\right)$ on a customdesigned probe tester. ${ }^{45}$ During a probe tack test, a flat ended probe of $1 \mathrm{~cm}$ in diameter is brought into contact with the adhesive film at a velocity of $30 \mu \mathrm{m} \mathrm{s}^{-1}$. The probe stays in contact with the PSA layer for $1 \mathrm{~s}$. The contact force is $70 \mathrm{~N}$ (corresponding to an average pressure of $1 \mathrm{MPa}$ for a probe fully in contact). The probe is then removed at a debonding velocity varying between 10 and $1000 \mu \mathrm{m} \mathrm{s}^{-1}$. During the test, the force as a function of the probe displacement is recorded. Stress vs. strain curves are then obtained by normalizing the force by the initial contact area between the probe and the adhesive layer and normalizing the displacement by the initial thickness of the PSA film. The choice of stainless steel as a standard probe surface was dictated by convenience. The degree of surface roughness which can be

important for soft adhesives ${ }^{46,47}$ is well controlled in the case of stainless steel surfaces. The flat ends of the probes were first polished with several grades of abrasive paper until a final average rms roughness of $0.1 \mu \mathrm{m}$, as measured with an optical profilometer, was found. The same probe was used throughout a series of tests, and its flat end was cleaned with water and acetone in between each measurement. 


\section{Rheological experiments}

The rheological experiments were performed on a RDAII rheometer fitted with a parallel-plate geometry. Shear amplitude scans were first performed at constant frequency but increasing strain amplitude (1\% to $20 \%$ ) to determine the linear regime. Then, frequency scans at a fixed shear amplitude of $16 \%$ were carried out for all samples between $0.01 \mathrm{~Hz}$ and $65 \mathrm{~Hz}$. The testing temperature was $30{ }^{\circ} \mathrm{C}$ for all samples.

\section{Results and Discussion}

Nano-mechanical Properties of Starting Materials: Acrylic and TR

In this section, we will report the structure and nanoscale mechanical properties of the starting "building block" components of the nanocomposite adhesive films. In the sections that follow, we will then consider mixtures of the components in nanocomposite films prepared by either miniemulsion polymerisation or by blending of the particles. Figure 3 shows images of the topography (height image) and the energy dissipation (phase image) of the pure latex ME-0 (Figs.3a-b) and the TR (Figs.3c-d).

ME-0 presents core-shell structures in the film morphology, as is clearly visible in the phase image (Fig.3b) where the shell appears brighter than the core, indicating that the shell is less energy dissipative, and thus is presumed to have a lower viscous component in the viscoelasticity (i.e. "harder"). It is possible to observe the core of the ME-0 particles presumably because the AFM tip indents the particles deep enough to "see" it. 


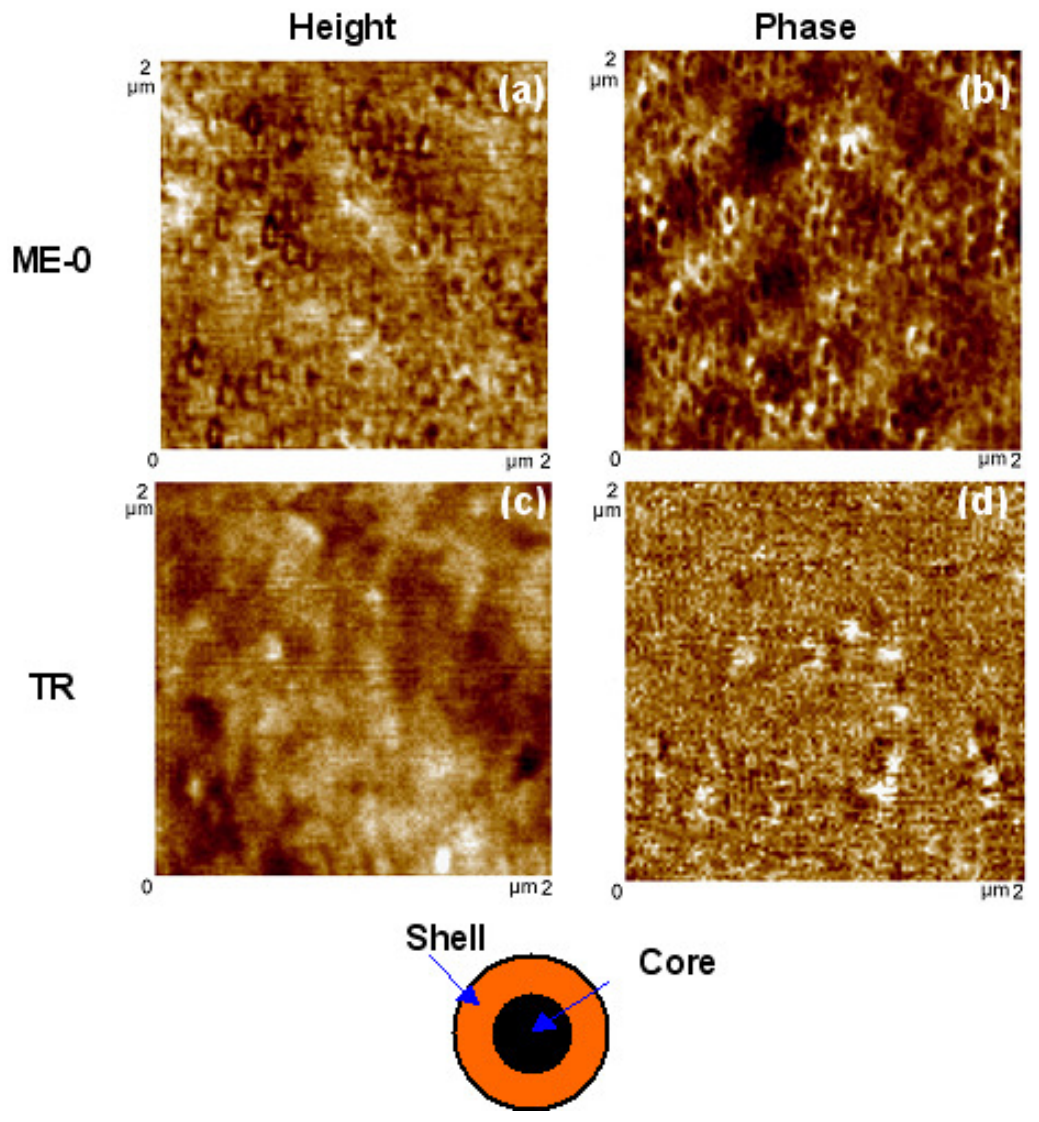

Figure 3. (a) Height and (b) phase images ( $2 \mu \mathrm{m} \times 2 \mu \mathrm{m}$ area) of ME- 0 ; the height scale is $0-$ $6 \mathrm{~nm}$ and the degree scale is $85.5^{\circ}-88.5^{\circ}$. (c) Height and (d) phase images ( $2 \mu \mathrm{m} \times 2 \mu \mathrm{m}$ area) of TR; the height scale is $0-4.5 \mathrm{~nm}$ and the degree scale is $95.5^{\circ}-97.5^{\circ}$ for TR. Core-shell structures are visible in the phase image of ME-0. A sketch of a core-sell structure is also given.

TR does not present any apparent particle structure, indicating that the particles have coalesced to form a uniform film (Fig.3d). As expected, the phase images for both ME-0 and TR do not show the presence of a second phase because they are pure acrylic and pure resin, respectively.

Examples of typical $F-d$ curves obtained from ME-0 and TR are presented in Fig.4a; For deformable materials, the AFM retraction curves do not simply probe adhesive interaction forces but also their coupling with the deformability. TR shows a very small and narrow 
adhesion peak owing to the high stiffness of the TR, which precludes a significant deformation of the TR during the detachment of the AFM tip, while the peak of ME-0 is large and broad, indicative of more polymer deformation.
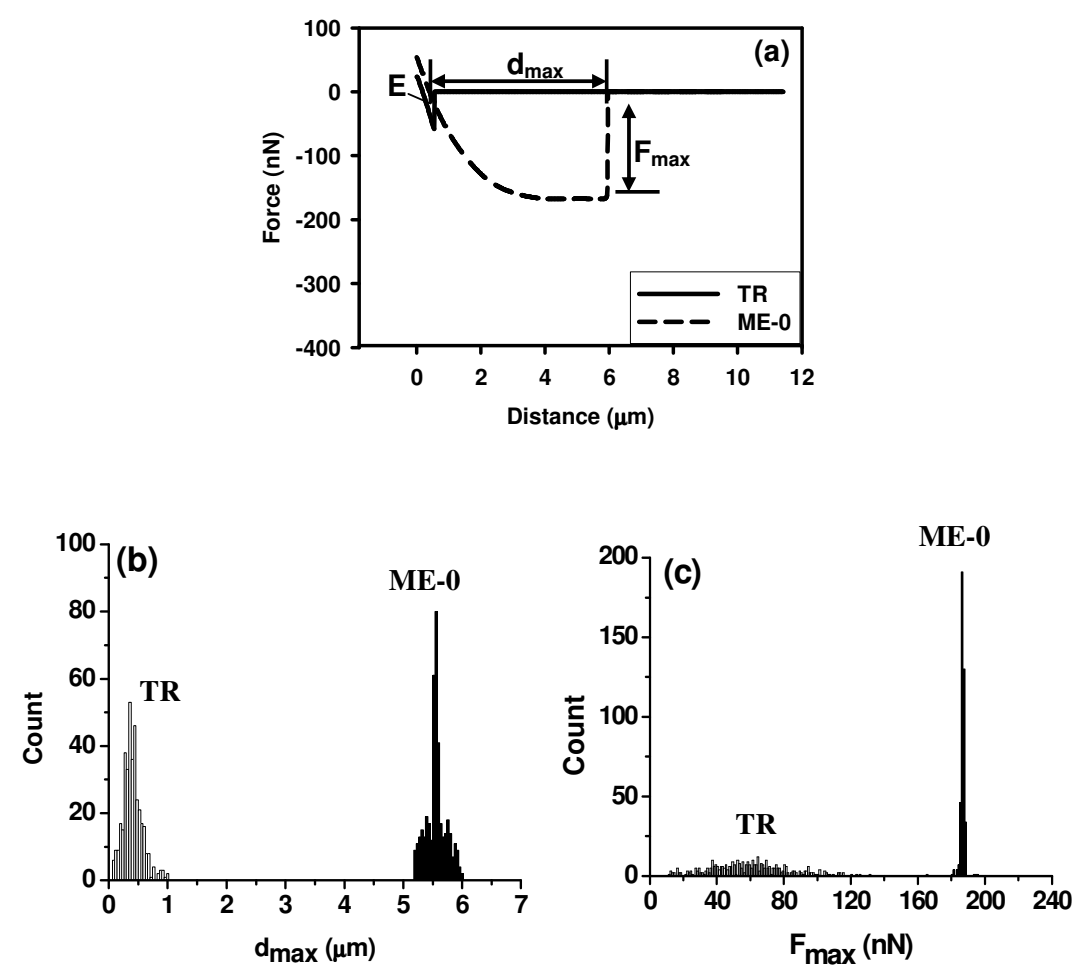

Figure 4. (a) Typical $F-d$ retrace curves for ME-0 and TR. Measurements of $d_{\max }, F_{\max }$, $W_{\text {adh }}$, and $E$ are shown. Histograms of the statistical distributions of (b) $d_{\max }$ and (c) $F_{\max }$ for ME- 0 and TR. Bin widths are $0.04 \mu \mathrm{m}$ for $d_{\max }$ and $1 \mathrm{nN}$ for $F_{\max }$.

Three important parameters were extracted from the $F-d$ spectra. $F_{\max }$ can be used as an indicator of the strength of the bonding between the tip and surface; $d_{\max }$ is an indicator of the extensibility of the material near the surface; $W_{\text {adh }}$ provides a measure of the energy that is spent in de-bonding of the tip from the surface combined with the energy required to deform the material near the surface.

Histograms showing the number distribution of $d_{\max }$ and $F_{\max }$ obtained from 400 independent measurements are displayed in Figures $4 \mathrm{~b}$ and c. (Although, the $F_{\max }$ values are 
negative in the FS curves, $F_{\max }$ values are presented as positive throughout this paper.) TR does not show any significant adhesion to the AFM tip, as is clearly indicated by the very low values for the mean $d_{\max }(0.36 \mu \mathrm{m})$ and $F_{\max }(66 \mathrm{nN})$ in Figs.4b-c. In addition, the $E_{\text {eff }}$ of the TR film (Table 2) is relatively high $(20 \mathrm{MPa})$, indicating that the TR is quite stiff. On the contrary, ME-0 has better adhesive properties as shown by its higher extensibility $\left(d_{\max }=5.5\right.$ $\mu \mathrm{m})$ and a higher adhesion force $\left(F_{\max }=187 \mathrm{nN}\right)$; it is much less stiff than the TR, with its very low $E_{\text {eff }}=0.12 \mathrm{MPa}$ (Table 2). These nano-scale measurements are qualitatively consistent with what is observed at the macro-scale.

Comparison of Miniemulsion Tackified Films and Blend Films: Nano-Scale Structures and Properties

We next consider the structure and properties of the two "building blocks" when they are blended as particles in comparison to when they are incorporated within the same particles via the core-shell miniemulsification process. The addition of $12 \mathrm{wt} . \%$ TR to the core of the miniemulsion (ME-12) leads to the appearance of a second phase in the morphology of the adhesive film (Figs.5a-b) compared to the pure acrylic latex ME-0 (Figs. 3a-d).

Table 2. Nanoscale mechanical property measurements of miniemulsion latex and their blends with tackifying resin

\begin{tabular}{|c|c|c|c|c|c|c|c|c|}
\hline \multirow[b]{2}{*}{ Code } & \multicolumn{2}{|c|}{$E_{\text {eff }}(\mathbf{M P a})$} & \multicolumn{2}{|c|}{$d_{\max }(\mu \mathrm{m})$} & \multicolumn{2}{|c|}{$F_{\max }(\mathrm{nN})$} & \multicolumn{2}{|c|}{$W_{\text {adh }}\left(10^{-15} \mathrm{~J}\right)$} \\
\hline & $\begin{array}{c}\text { Lower } \\
\text { population }\end{array}$ & $\begin{array}{c}\text { Upper } \\
\text { Population }\end{array}$ & $\begin{array}{c}\text { Lower } \\
\text { Population }\end{array}$ & $\begin{array}{c}\text { Upper } \\
\text { Population }\end{array}$ & $\begin{array}{c}\text { Lower } \\
\text { Population }\end{array}$ & $\begin{array}{c}\text { Upper } \\
\text { Population }\end{array}$ & $\begin{array}{c}\text { Lower } \\
\text { Population }\end{array}$ & $\begin{array}{c}\text { Upper } \\
\text { Population }\end{array}$ \\
\hline TR & na & 20 & 0.36 & $\mathrm{Na}$ & 66 & na & 10 & na \\
\hline ME-0 & 0.12 & na & na & 5.5 & na & 187 & na & 346 \\
\hline ME-4 & 0.25 & na & na & 4.6 & na & 177 & na & 275 \\
\hline ME-12 & 0.036 & na & 2.1 & 4.2 & na & $296 / 340$ & 384 & 775 \\
\hline $\begin{array}{c}\text { PB: } \\
\text { ME-0+12\% TR }\end{array}$ & 0.25 & 1.35 & 0.9 & 4.6 & 66 & 91 & 13.5 & 248 \\
\hline $\begin{array}{c}\text { PB: } \\
\text { ME-4 +8\% TR }\end{array}$ & 0.23 & 1.47 & 0.5 & 4.5 & 67 & $157 / 192$ & 12 & $412 / 612$ \\
\hline
\end{tabular}

na $=$ not applicable 


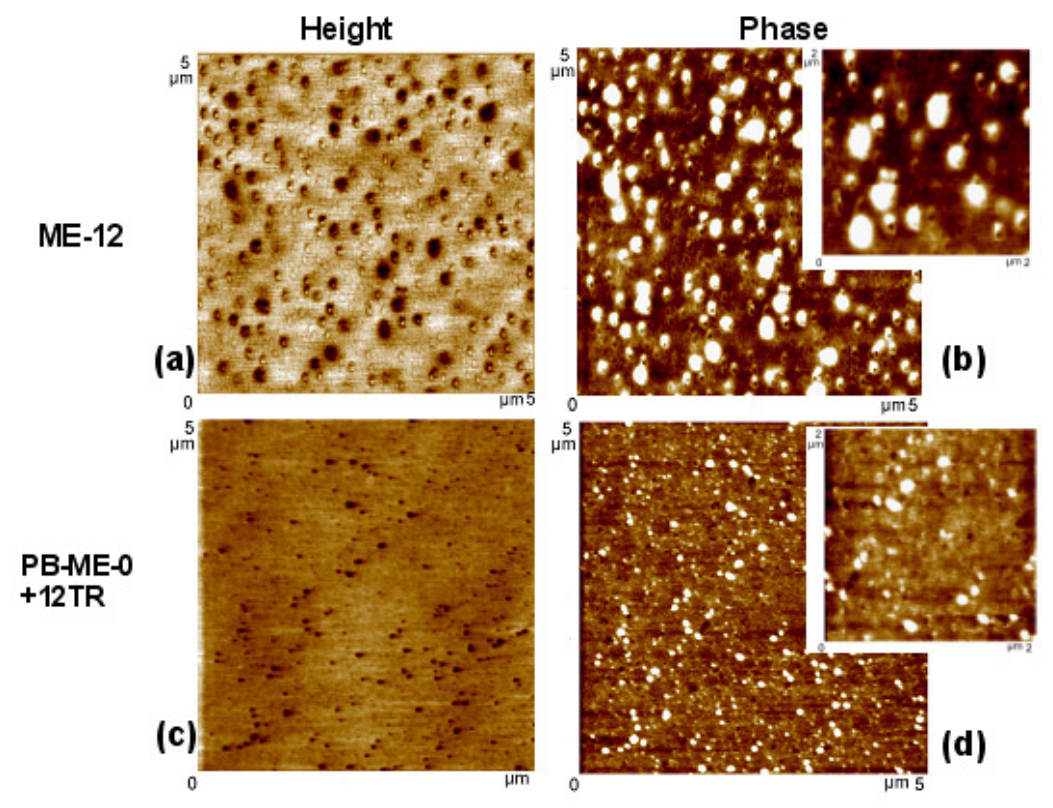

Figure 5. (a) Height and (b) phase images ( $5 \mu \mathrm{m} \times 5 \mu \mathrm{m}$ area) of ME-12. The inset shows a $2 \mu \mathrm{m} \times 2 \mu \mathrm{m}$ high-resolution image. The height scale is $0-16 \mathrm{~nm}$ and the degree scale is $83^{\circ}-94^{\circ}$. Core-shell structures of ME-12 and tackifier-rich aggregates (bright spots) are visible in the phase image; (c) height and (d) phase images ( $5 \mu \mathrm{m} \times 5 \mu \mathrm{m}$ area) of PB-ME$0+12 \% \mathrm{TR}$. The inset shows a $2 \mu \mathrm{m} \times 2 \mu \mathrm{m}$ high-resolution image. The height scale $0-25$ $\mathrm{nm}$ and the degree scale is $88^{\circ}-99^{\circ}$. Coalesced particles are visible in the phase image along with pure TR (bright spots).

The phase image (Fig.5b) shows the presence of a second component that appears bright in the image. The brightness of this component indicates that it does not dissipate as much energy in AFM tip interaction as does the continuous matrix, which appears darker. The former has a lower viscous component than the latter. Drawing on what was learned from the study of the individual components, we presume that the brighter spots represent TR-rich regions. The size of some of these TR-rich regions ( $c a .110 \mathrm{~nm}$ diameter) is larger than the particle size (ca. $41 \mathrm{~nm}$ diameter). It seems, therefore, that the TR was not incorporated in 
equal concentrations in the population of particles during miniemulsion polymerisation. There is clearly a heterogeneous distribution of the TR; if the two phases had been blended at the molecular level, then a large phase contrast would not be apparent. Furthermore, the TR has not been homogenized by diffusion during the film formation process.

The physical blend (admixture) of ME-0 and 12 wt.\% waterborne TR (PB-ME$0+12 \%$ TR, where PB designates "physical blend and it is followed by the two components in the mixiture and concentration of tackifying resin (TR)), is considered next. AFM images (Figs.5c-d) show the presence of two components. In the phase image (Fig.5d), bright spots are visible that could be pure TR resin. The dimension of these bright spots is nearly half that of the spots observed in the tackified miniemulsion film, ME-12 (Fig.5b). Rather surprisingly, the TR-rich regions in the blend film are distributed on a finer length scale than what was found in the miniemulsion system. The core-shell latex particles appear to have coalesced, making it difficult to distinguish individual particles. This result is similar to what was observed by Mallégol et al. when they imaged by AFM a blend of an acrylic PSA with waterborne TR. ${ }^{20}$ The addition of TR in the PSA blend induced the coalescence of acrylic particles, possible because it acted as a "solid solvent".

AFM images provide qualitative information on the structure, but FS maps provided quantitative information on the components and their distribution (Fig.6). Typical $F-d$ curves for the miniemulsion ME-12 and the physical blend of ME-0 and 12 wt.\% waterborne TR (PBME- $0+12 \%$ TR) are compared in Fig. 6a. The huge difference between the dimensions of the adhesion peaks illustrates a dramatic increase of the nano-scale adhesive properties when 12 wt. $\%$ of TR is incorporated into the acrylic latex particles. Moreover, the $F-d$ curve for ME-12 shows two adhesion peaks, which are attributed to the onset of fibrillation when the polymer film was stretched during the FS experiment, according to an interpretation reported elsewhere. $^{48}$ 

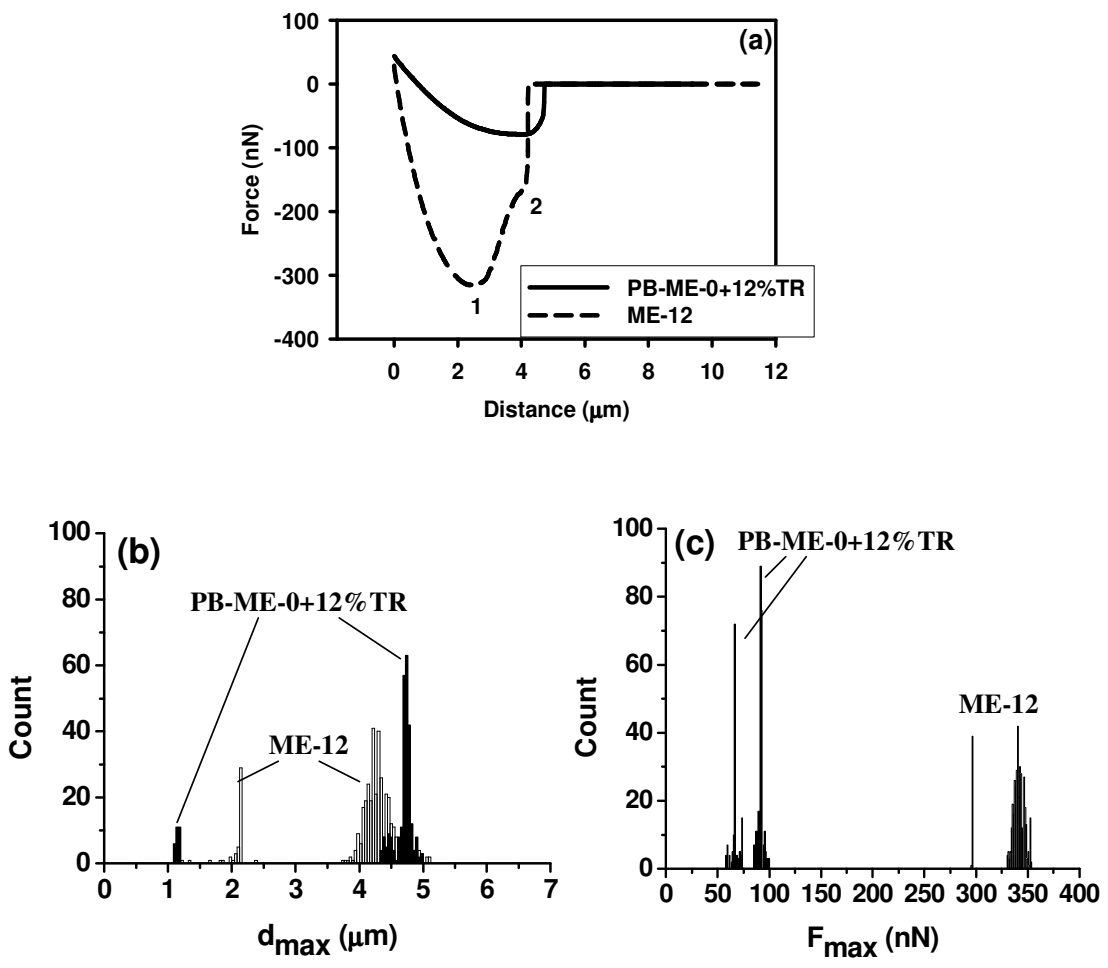

Figure 6. (a) Typical $F-d$ retrace curves for PB-ME-12+12\% TR and ME-12. The numbers identify two peaks. Histograms of the statistical distributions of (b) $d_{\max }$ and (c) $F_{\max }$ for PBME-12+12\% TR and ME-12. Bin widths are $0.04 \mu \mathrm{m}$ for $d_{\max }$ and $1 \mathrm{nN}$ for $F_{\max }$.

Two distinct populations can be observed in the histograms of the statistical distributions of $d_{\max }$ and $F_{\max }$ for ME-12 (Figs.6b-c). One population corresponds to a possible TR-rich component (mean $d_{\max }=2.1 \mu \mathrm{m} ; F_{\max }=296 \mathrm{nN}$ ) and the other population to an acrylic-rich, tackified component (mean $d_{\max }=4.2 \mu \mathrm{m} ; F_{\max }=340 \mathrm{nN}$ ). Notably, $F_{\max }$ for ME12 is far greater than for ME-0 (Fig. 4c), which shows the positive effect of the TR in increasing the adhesion at the nano-scale. In addition, ME-12 is much less stiff than ME-0, as its $E_{\text {eff }}$ is much lower (Table 2). We conclude that the effect of miniemulsion tackifer incorporation is to increase the adhesive force and the energy dissipation of the acrylic film. Interestingly, the maximum extension of the $F-d$ curves does not change relative to ME-0 
implying that the network architecture of the gel fraction of the adhesive has not been significantly changed.

The values of $d_{\max }$ and $F_{\max }$ for the so-called TR-rich components are much greater than those obtained for the pure TR (Table 2). This result indicates that there is no "pure" TR in the miniemulsion films but rather there is a molecular-scale mixture of TR and acrylic. Therefore, there is evidence that the TR resin was incorporated in the acrylic during the two-stage miniemulsion process and subsequent film formation.

The presence of two separate phases in the physical blend (PB-ME- $0+12 \% \mathrm{TR}$ ) is confirmed by FS, and quantitative comparisons can be made. Two different populations can be clearly distinguished in the histograms of the statistical distributions of $d_{\max }$ and $F_{\max }$ (Figs.6bc) and in $E_{\text {eff }}$ (Table 2). The values of the lower population $\left(d_{\max }=0.9 \mu \mathrm{m} ; F_{\max }=66.1 \mathrm{nN}\right)$ are relatively close in value to those found for the pure TR. The upper population's values $\left(d_{\max }=\right.$ 4.6 $\left.\mu \mathrm{m} ; F_{\max }=91.5 \mathrm{nN}\right)$ are both less than the pure acrylic (ME-0) (Table 2). The great magnitude in the difference between the two phases is probably due to the fact that the acrylic and the TR are not fully miscible, but create heterogeneities at the nano-scale. The lower population can be considered to be primarily TR, whereas the upper population can be attributed to a tackified acrylic, resulting from some miscibility of the components.

Considering the pure acrylic (ME-0) in comparison to the $12 \%$ TR physical blend with acrylic, a hardening is found, as $E_{\text {eff }}$ increases from $0.12 \mathrm{MPa}$ to $0.25 \mathrm{MPa}$, but $F_{\max }$ falls from $187 \mathrm{nN}$ to $91.5 \mathrm{nN}$ when TR is added. This hardening is indicative of some miscibility of the phases leading to some incorporation of the TR within the acrylic. It may also be that the TR acts as a rigid filler at a small scale and has the effect of adding an additional crosslinker and forming a tighter network.

In both the miniemulsion and the blend adhesives, heterogeneities in the components at the nano-scale exist. The FS mapping experiments enable the visualisation of the structure in a 
quantitative way. $W_{\text {adh }}$ determined from each of the $F-d$ measurements is presented in a $20 \mathrm{x}$ 20 array in Figure 7, in which the gray-scale is indicative of the magnitude. As found in the AFM images, the distribution of the TR-rich phase is finer and more uniform in the physical blend film in comparison to the ME-12 film.
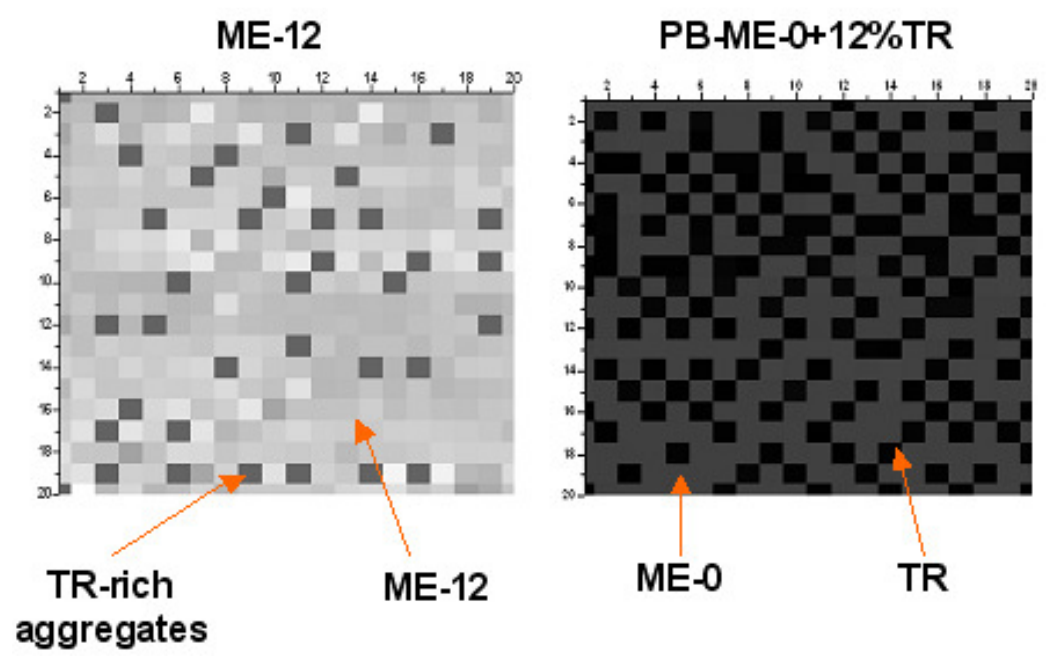

Figure 7. Energy ( $\left.W_{\text {adh }}\right)$ maps of ME-12 (at left) and PB-ME-0+12\%TR (on the right). Both maps have the same gray scale, ranging from 0 to $10^{-12} \mathrm{~J}$.

\section{Effect of TR on the macro-scale properties}

The macro-scale adhesion properties of the two-stage tackified core-shell PSA latexes were investigated by performing probe-tack measurements. During a probe-tack experiment, the probe exerts a negative pressure on the polymer film that can lead to the growth of cavities at the probe-polymer film interface. ${ }^{49}$ The peak of the stress-strain curve corresponds roughly to the point at which the maximum number of cavities is formed. At this point, the cavities propagate laterally or vertically. The walls between the cavities become thinner, and they form a foam oriented in the tensile direction. When the fibrils detach from the adherend, the stress falls to zero. In the case of a cohesive failure of the fibrils, the stress tends to drop more gradually because the fibrils become thinner before breaking. ${ }^{50}$ 
A comparison at the macro-scale of ME-0 with the physical blend PB-ME- $0+12 \%$ TR is made in Figures 8. The stress-strain curves (Fig.8a) do not show large differences for the two systems. However, the stress at the plateau for PB-ME-0+12\%TR is higher and its extension slightly longer compared to that for ME-0, indicating that the TR has introduced a hardening effect and more energy dissipation. As the introduction of TR by physical blending does not involve any chemical reaction, this hardening cannot be due to an over crosslinking of the polymer. A more plausible explanation is that the TR domains (observed in AFM images) act as nano-scale hard fillers and reinforce the matrix.
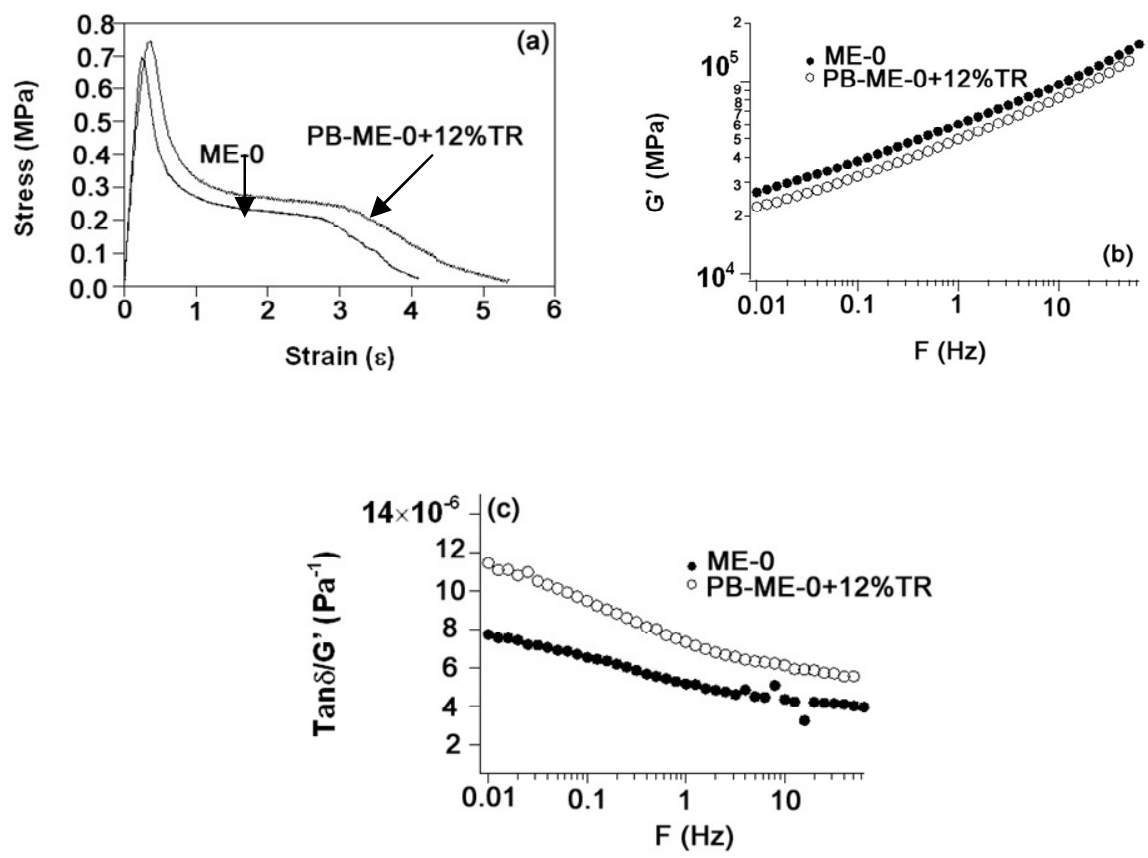

Figure 8. Macro scale measurements of ME-0 in comparison to PB-ME-0+12\%TR (a) Probe tack curves at $V_{\mathrm{deb}}=100 \mu \mathrm{m} / \mathrm{s} ;(\mathrm{b}) ; G^{\prime}$ as a function of frequency and (c) the ratio $\tan \delta / G^{\prime}$ as a function of frequency.

When TR resin is incorporated in the core of the miniemulsion (ME-12), the plateau is lower (Fig.9a) than that for ME-0 and PB-ME-0+12\% TR, indicating that the polymer is more easily deformable. The longer length of the plateau compared with that of ME- 0 and PB-ME- 
$0+12 \%$ TR shows either that the viscous component of ME-12 is much higher (i.e. more liquidlike), allowing the fibrils to be drawn farther, or that the finite extensibility of the gel fraction has increased. There is indeed evidence that the TR resin is acting as a transfer agent: the average molecular weight of ME-12 was lower than in ME-0. Furthermore, as shown in Figure 10, the gel fraction of the minemulsion polymers was found to decrease with increasing TR inclusion. These effects are likely to be the cause of the softening of ME-12 compared to PBME- $0+12 \%$ TR.
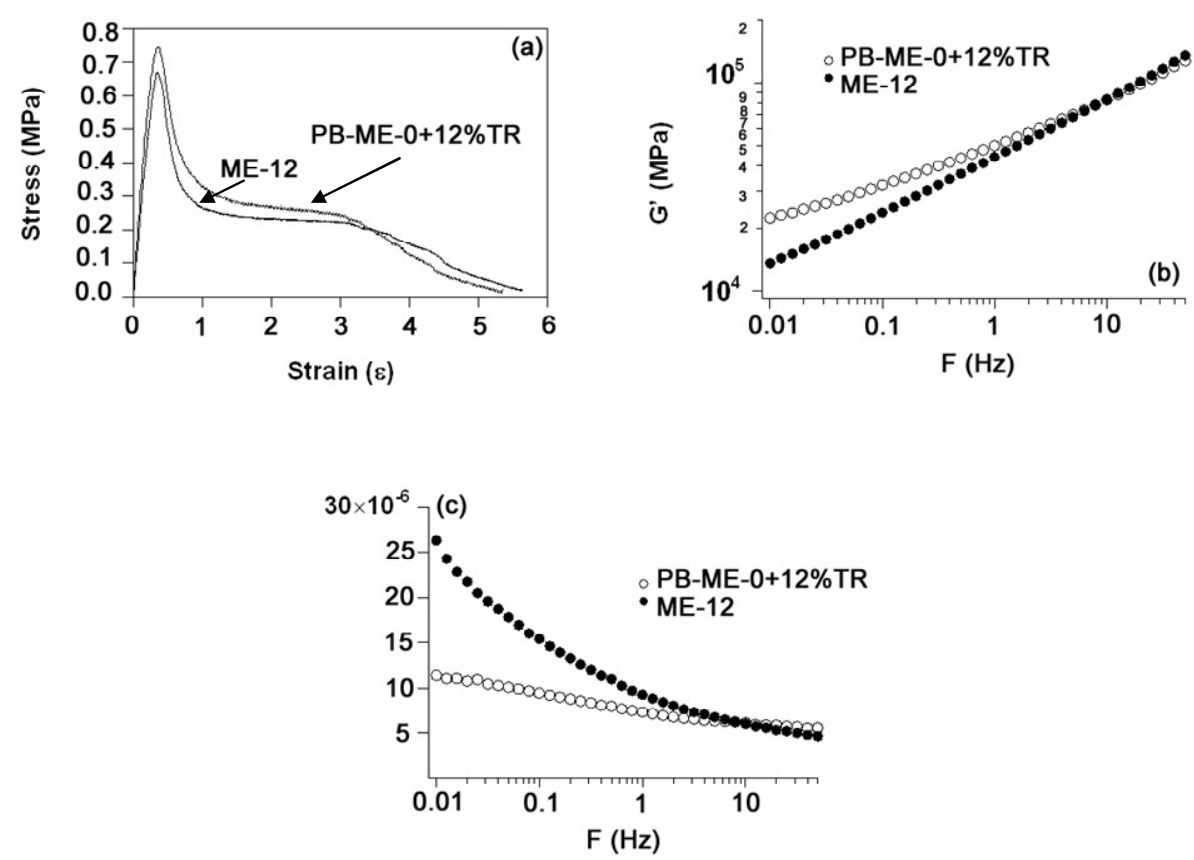

Figure 9. Macro-scale measurements of ME-12 and PB-ME-0+12\%TR (a) Probe-tack stressstrain curves at $V_{\mathrm{deb}}=100 \mu \mathrm{m} / \mathrm{s}$; (b) elastic modulus, $G^{\prime}$; and (c) the ratio $\tan \delta / G^{\prime}$ as a function of frequency. 


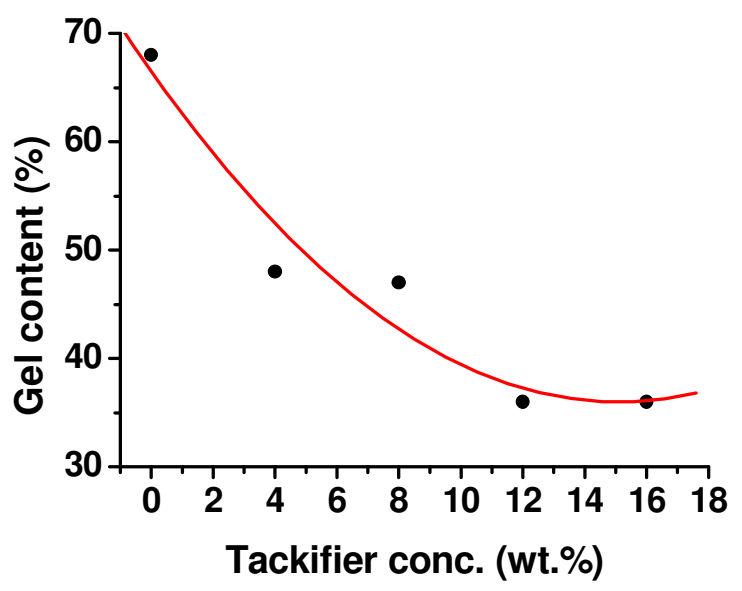

Figure 10. Gel content as a function of tackifier content in a series of tackified miniemulsion latex polymers.

To understand these macroscopic adhesion results, it is instructive to consider the viscoelastic properties of the latex films obtained from rheological measurements. In the linear viscoelastic regime, the physical blend of the acrylic with 12 wt.\% TR resin (PB-ME$0+12 \%$ TR) is very similar (Fig. 8 b) to the pure acrylic. On the contrary, the 12 wt.\% miniemulsion (ME-12) was less stiff (lower G', at least at low frequencies) and more dissipative (Fig.9b). The decrease in $G^{\prime}$ of ME-12 compared to ME-0 is in agreement with the increase in $E_{\text {eff }}$ shown by the FS results (Table 2). Hence, at low strain rates the macro-scale tensile deformation is consistent with the nano-scale deformation properties.

A micromechanical model has shown $n^{51,52,53}$ that the ratio of the loss tangent to the storage modulus $\left(\tan \delta / G^{\prime}\right)$ between viscoelastic properties is a good predictor of the adhesion energy. The higher that $\tan \delta / G^{\prime}$ is, then the greater is the extension of the adhesive before it detaches from the substrate. The pure acrylic (ME-0) has the lowest $\tan \delta / G^{\prime}$ value (Fig.8c), while the tackified miniemulsion ME-12 shows the highest values (Fig.9c). This result is consistent with the observed increase in the adhesion energy when incorporating the TR resin inside the cores of the particles. A similar trend for the adhesion energy was obtained in the 
nano-scale measurements (Table 2), which showed that the incorporation of the resin inside the core of the acrylic during miniemulsion led to a sharp increase in the $W_{\text {adh }}$ and $F_{\max }$ of the PSA.

\section{Blend of Miniemulsion Tackified Latex with Additional Tackifer: A More Fair Comparison}

As has already been pointed out, the molecular weight distribution and the gel content of the acrylic phase is affected by TR in the miniemulsion polymerization process. Hence, it is not surprising that the properties of the blend and miniemulsion materials differ, when considering the differences in the polymer architecture in the acrylic phase. To make a more fair comparison, a blend of a miniemulsion latex containing 4 wt.\% tackifying resin in the core (ME-4) and 8 wt.\% TR (PB-ME-4 + 8\% TR) is considered. This blend film contains 12 wt.\% tackifying resin in total, and its acrylic component will be similar at the molecular level to the acrylic in ME-12, thus enabling a fairer comparison.

ME-4 films (Figs.11a-b) show the presence of individual latex particles; complete coalescence is not observed. However, unlike ME-12 (Fig.5b), the phase images for ME-4 (Fig.11b) do not show any core-shell structures, as the particles do not have a shell. Just a few small bright spots (average diameter of $63 \mathrm{~nm}$ ) are visible and could be TR-rich components. However, the very small dimensions of these domains and their low number indicate that most of the TR was incorporated in the acrylic and distributed equally between the particles during the miniemulsion polymerization process. 

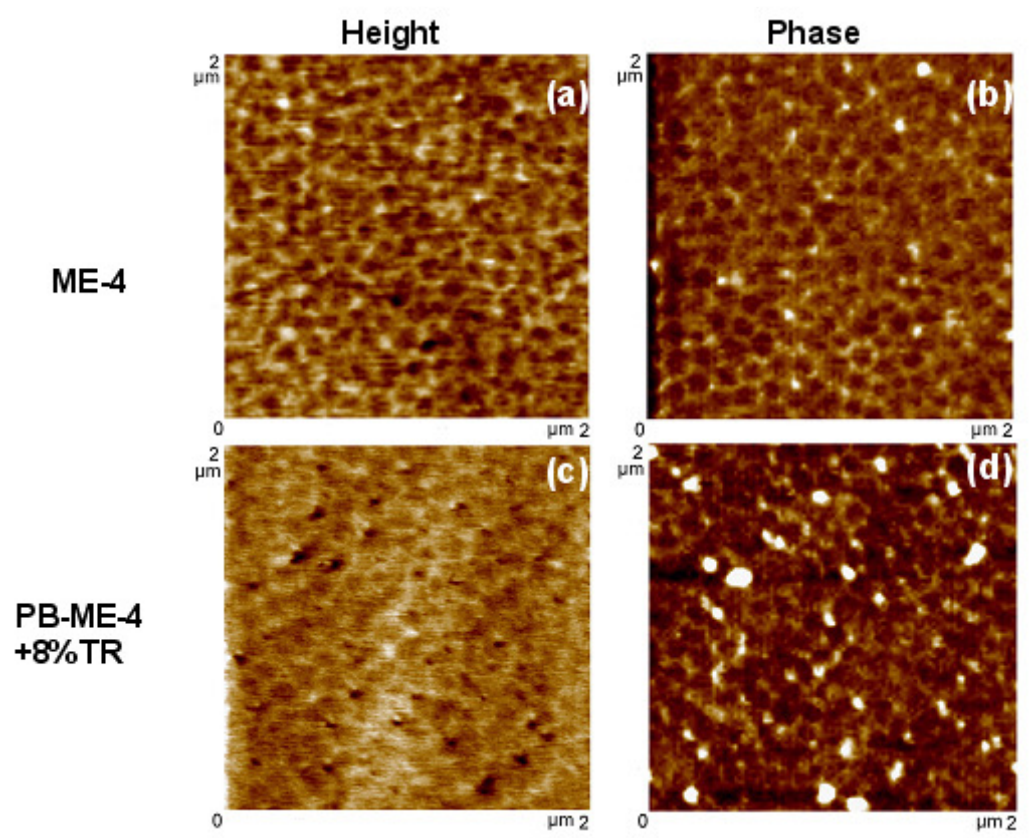

Figure 11. (a) Height and (b) phase images (2 $\mathrm{mm}$ x $2 \mu \mathrm{m}$ area) of ME-4. The height scale is $0-$ $9 \mathrm{~nm}$ and the degree scale is $82^{\circ}-85.5^{\circ}$. (c) Height and (d) phase images ( $2 \mu \mathrm{m} \times 2 \mu \mathrm{m}$ area) of PB-ME-4+8TR. The height scale is $0-10 \mathrm{~nm}$ and the degree scale is $86^{\circ}-90^{\circ}$.

A comparison of the phase images for ME-12 (Fig.5b) with those for ME-4 (Fig.11b) shows that the higher the TR content in the miniemulsion, the larger the number and dimension of the less-dissipative particles. There might be a concentration limit above which it is not possible to maintain a uniform distribution of tackifying resin in the population of particles. Blending 8 wt.\% TR resin with ME-4 (PB-ME-4+8\% TR) increased the number of bright spots, possibly pure TR, visible in the phase image (Fig.11d).

Figure 12a shows examples of $F-d$ curves for ME-4 and PB-ME-4+8\%TR. Although there is not a large difference in the two adhesion peaks, the height of the peak for the physical blend (PB-ME-4+8\%TR) is slightly larger than that of the peak for the ME-4, while the width of these two peaks is roughly the same.

Histograms obtained from the FS experiments on ME-4 (Fig.12b and c) support the hypothesis that most of the tackifying resin was incorporated in the core of the miniemulsion 
particles, because only one population for $d_{\max }$ and $F_{\max }$ is found. On the other hand, two different populations are present in the $d_{\max }$ histogram for the blend of ME-4 and 8 wt.\% TR (Fig.12b), one corresponding to the TR $\left(d_{\max }=0.5 \mu \mathrm{m}\right)$ and the other corresponding to the acrylic latex $\left(d_{\max }=4.5 \mu \mathrm{m}\right)$. There is greater heterogeneity in the blend in comparison to the miniemulsion film. These results are similar to those obtained for PB-ME-0+12\% TR.

Surprisingly, the histogram for $F_{\max }$ (Fig.12c) shows three populations: $F_{\max }=67 \mathrm{nN}$ (similar to TR), $F_{\max }=192 \mathrm{nN}$ (similar to ME-0), and an intermediate value of $F_{\max }=157.5$ $\mathrm{nN}$. The intermediate population can be attributed to a phase created by interdiffusion between the acrylic and TR but that did not influence $d_{\max }$.

The energy map for ME-4 (Fig.13) shows greater homogeneity in comparison to the energy map for the physical blend PB-ME-4+8\%TR, which is consistent with the AFM images. In the blend, the two phases are very well separated by a high contrast between them, further confirming that the TR does not blend uniformly with the acrylic at the molecular level. The measurements of $E_{\text {eff }}$ gave two different statistical populations (Table 2), broadly in line with what was found with the ME-0 + 12 wt.\% TR blend. 

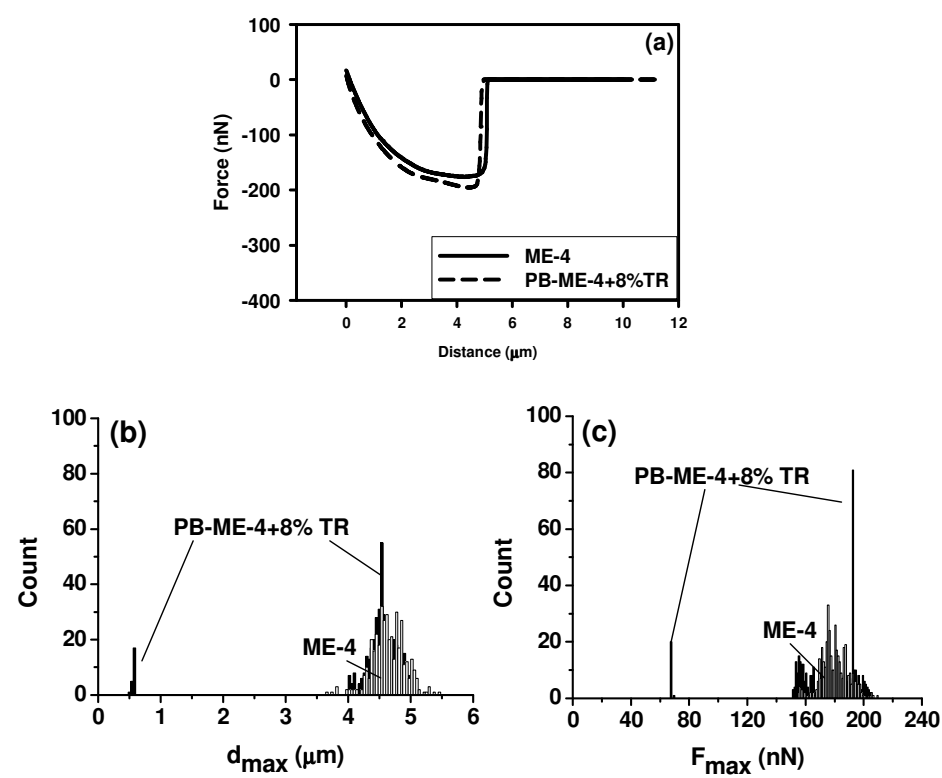

Figure 12. (a) Typical $F-d$ curves for PB-ME-4+8\% TR and ME-4. Histograms of the statistical distributions of (b) $d_{\max }$ and (c) $F_{\max }$ for PB-ME-4+8\% TR and ME-4. Bin widths are $0.04 \mu \mathrm{m}$ for $d_{\max }$ and $1 \mathrm{nN}$ for $F_{\max }$.

ME-4

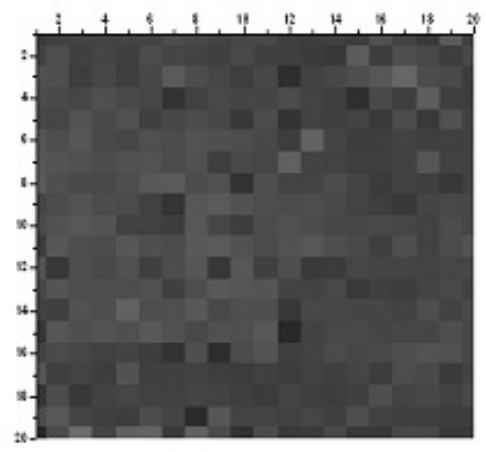

PB-ME-4+8\%TR

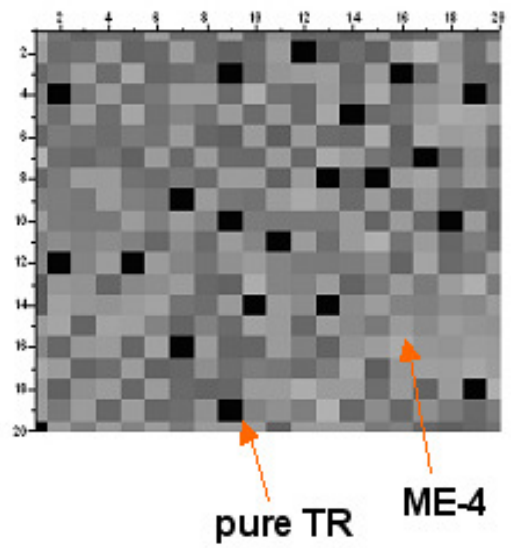

Figure 13. Energy ( $\left.W_{\text {adh }}\right)$ maps of ME-4 (left) and a blend with TR (PB-ME-4+8\%TR) (right). Both maps have the same gray scale, ranging from 0 to $10^{-12} \mathrm{~J}$. 
Although the $d_{\max }$ values for ME-4 (Fig.12b) and ME-12 (Fig.6b) are similar, the $F_{\max }$ for ME-4 (Fig.12c) is half of that measured for ME-12 (Fig.6c). This result shows that the inclusion of more TR increases the adhesion force without the loss of extensibility.

The key comparison to make is between the tackified miniemulsion film, ME-12, and the corresponding physical blend of ME-4 and $8 \mathrm{wt} . \%$ TR. Here, the extensibility, as measured by $d_{\max }$, of the upper populations in the miniemulsion and the blend are approximately equal. A significant difference is seen, however, in the $F_{\max }$ and the $W_{\text {adh }}$ values of the populations, with the miniemulsion film having higher values. The most important conclusion we draw from the nano-scale analysis is that the adhesion energy is greatest when the TR is incorporated in the polymer particles (albeit non-uniformly across the population) rather than when blended at the particle level. Elsewhere, the increase at the nanoscale of the adhesive properties of solvent-cast polymers resulting from the presence of TR has been demonstrated by AFM nanomechanical measurements. ${ }^{23}$

\section{Macro-scale Properties: ME-4 and its blend with 8\% TR}

Figure 14a shows the probe-tack stress-strain curves of ME-4 and PB-ME-4+8\% TR at $V_{\mathrm{deb}}=10 \mu \mathrm{m} / \mathrm{s}$. The curve for the miniemulsion (ME-4) polymer shows a long plateau, which indicates a decrease in cohesion, which is attributed to the absence of the shell. Blending ME-4 with 8 wt.\% TR resin leads to polymer hardening as shown by an increase in the height of the plateau and a decrease of its length. Fibrils are drawn but they detach much earlier than those formed by ME-4. As was also observed at the nano-scale, these findings show that adding the TR inside the particle cores increases the adhesion energy of the polymer. On the contrary, if the TR is merely blended with the acrylic, it acts as a rigid filler and the polymer becomes stiffer and less energy dissipative, leading to a lower adhesion energy. 
In the linear viscoelastic regime, the physical blending of 8 wt. $\%$ TR with the $4 \%$ tackified miniemulsion polymer (PB-ME-4+8\% TR) does not have a significant effect on the storage modulus $G^{\prime}$ (Fig.14b). However, in this case the miniemulsion (ME-4) polymer has a higher $\tan \delta / G$, value (at least at low frequency) compared to its blend with 8\% TR (Fig.14c), explaining why it has a longer plateau in the tack curve and a greater adhesion energy. A similar result was observed for the adhesive energy obtained from the nanomechanical measurements (Table 2).
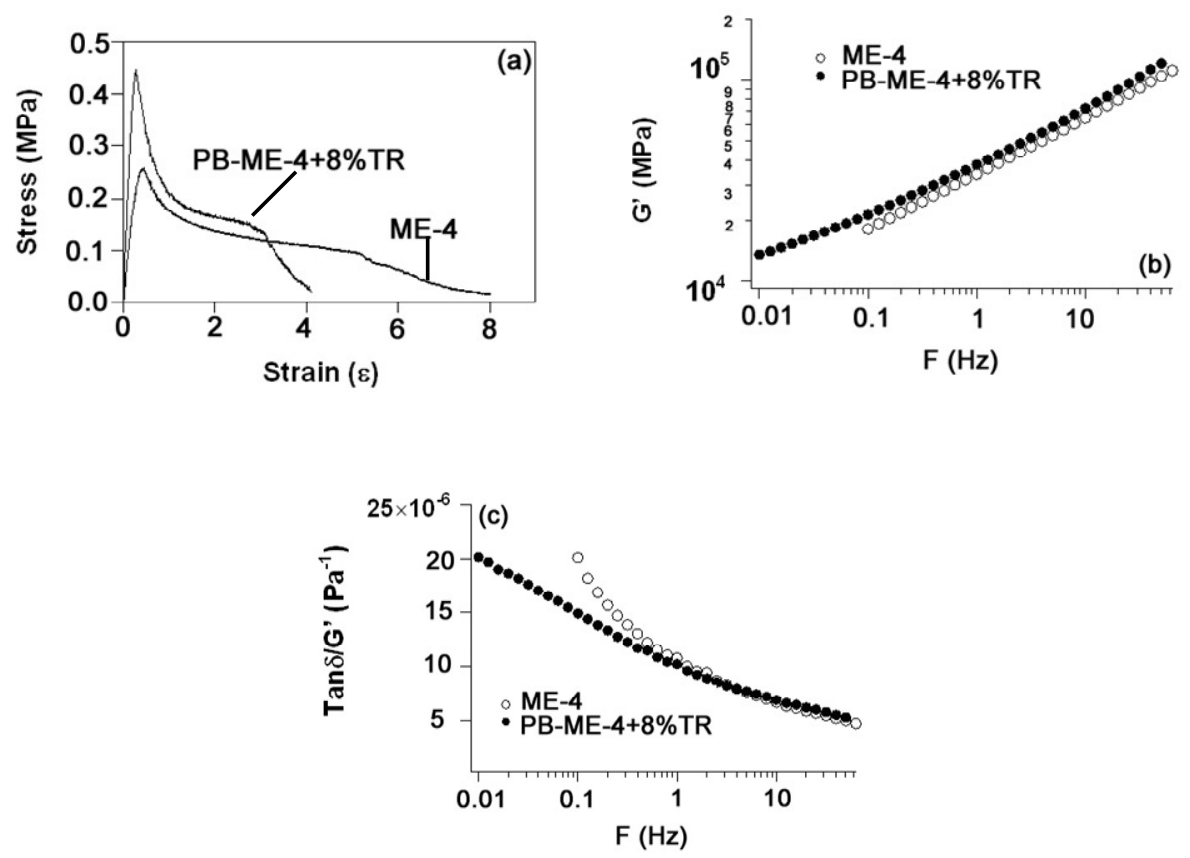

Figure 14. Macro scale measurements of ME-4 and PB-ME-4+8\%TR. (a) Probe-tack stressstrain curves at $V_{\mathrm{deb}}=10 \mu \mathrm{m} / \mathrm{s}$; (b) storage modulus, G'; and (c) the ratio tan $\delta / \mathrm{G}^{\prime}$ as a function of frequency.

\section{Conclusions}

A new approach to the incorporation of TR in waterborne acrylic PSAs has been developed by encapsulating it in individual particles via miniemulsion polymerization. We 
have found that the sub-mm structure and properties of these PSA films differ from what is obtained from blends of colloidal tackifier and latex particles. AFM imaging showed two distinct phases in the miniemulsion particles: TR-rich aggregates and core-shell structures. There was no evidence from force-spectroscopy for the presence of pure TR. AFM imaging and FS indicated that with $4 \mathrm{wt} . \%$ TR in the miniemulsion particles (ME-4), incorporation into the acrylic was more complete; there were fewer TR-rich regions. Blends of the TR with the acrylic showed the presence of nearly pure phases in AFM force spectroscopy, indicating that they were not miscible and poorly blended at the molecular level. AFM force spectroscopy showed that incorporation of $12 \mathrm{wt} \%$ TR by miniemulsion polymerisation enhanced the nanomechanical and adhesive properties of the PSA. Whereas information on the nanostructure is obtained with high resolution from AFM imaging, quantitative information was provided by force spectroscopy, but with low spatial resolution.

When the acrylic was blended with the TR, a hardening of the adhesive could be observed at the macro-scale. On the contrary, TR incorporation by miniemulsion polymerisation increased the adhesion energy and maximum adhesion force. These results show that the incorporation of TR through a miniemulsion polymerisation process not only offers benefits in the processing of the adhesive, but it also leads to enhanced adhesion properties.

\section{Acknowledgements}

Funding for this work was provided by the European Commission's Framework 6 Programme (NsHAPe project, Contract No. 505442). We are grateful to Prof. P.A. Lovell (University of Manchester), Ismo Pietari (Raflatac) and Tuija Helin (Raflatac) for many useful discussions. 


\section{TOC Image}

A Comparison of Tackified, Miniemulsion Core-Shell Acrylic Latex Films with Corresponding Particle-Blend Films: Structure-Property Relationships

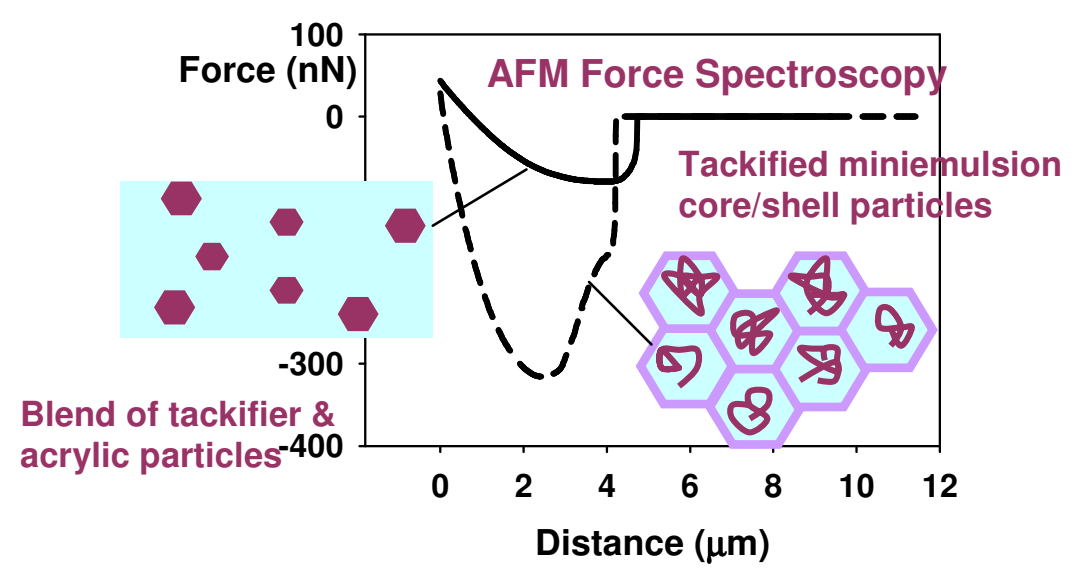




\section{References}

(1) Creton, C. MRS Bulletin 2003, 28, 434-439.

(2) Satas, D. Handbook of Pressure Sensitive Adhesive Technology; Van Nostrand Reinhold Book: New York, 1989.

(3) Lovell, P.A., El-Aasser, M.S. Emulsion Polymerisation and Emulsion Polymers, John Wiley and Sons Ltd, 1997.

(4) Padget, J. C. J. Coat. Technol. 1994, 66, 89.

(5) Jotischky, H. Surf. Coat. Int. 2001, 84, 11.

(6) Jovanovic, R.; Dube, M.A. J. Macromol. Sci. Polym. Rev. C 2004, 44, 1.

(7) Tobing, S.D.; Klein, A. J. Appl. Polym. Sci. 2001, 79, 2230-2244.

(8) Mulvihill, J.; Toussaint, A. ; De Wilde, M. Prog. Org. Coat. 1997, 30,127.

(9) Aramendia, E.; Barandiaran, M.J.; Grade, J.; Blease, T.; Asua, J.M. Langmuir 2005, 21, 1428.

(10) Donkus, J. L., Adhesives Age 1997, 40, 32-37.

(11) Sheriff, M.; Knibbs, R.W.; Langley, P.G. J. Appl. Polym. Sci. 1973, 17, 34233438.

(12) Class, J.B.; Chu, S.G. J. Appl. Polym. Sci. 1985, 30, 805.

(13) Aubrey, D.W.; Sherriff M. J. Polym. Sci. Polym. Chem. Ed. 1978, 16, 26312643.

(14) Young, R.H.; Tancrede, J.M. in Adhesives in Manufacturing; G.L. Schneberger Ed.; CRC Press: New York, 1983; Chapter 10.

(15) Paiva, A., Sheller N., Foster M.D., Crosby, A.J., Shull, K.R. Macromolecules 2000, 33, 1878-1881.

(16) Comyn, J. Int. J. Adhes. Adhesives 1995, 15, 9-14. 
(17) Jeusette, M.; Peeterbroeck, S.; Simal, F.; Cossement, D.; Roose, P.; Leclère, Ph.;

Dubois, Ph.; Hecq, M.; Lazzaroni, R. Eur. Polym. J. 2008, 44, 3931-3940.

(18) Paiva, A., Sheller N., Foster M.D., Crosby, A.J., Shull, K.R. Macromolecules 2001, 34, 2269-2276.

(19) Moon, S.; Foster, M.D. Langmuir 2002, 18, 1865-1871.

(20) Kim, H.J.; Hayashi, S.; Mizumachi, H. J. Appl. Polym. Sci. 1998, 69, 581-587.

(21) Simal, F.; Jeusette, M.; Leclère, Ph.; Lazzaroni, R. ; Roose, P. J. Adhesion Sci. Technol. 2007, 21, 559-574.

(22) Moon, S.; Foster, M.D. Langmuir 2002, 18, 8108-8115.

(23) Moon, S.; Swearingen, S.; Foster, M.D. Polymer, 2004, 45, 5951-5959.

(24) Jia, S.; Foster, M.D. J. Appl. Polym. Sci. 2002, 84, 400-404.

(25) Tobing, S.D.; Klein, A. J. Appl. Polym. Sci. 2000, 76, 1965-1976.

(26) Mallégol, J.; Bennett, J.; McDonald, P.J.; Keddie, J.L.; Dupont, O. J. Adhes. 2006, 82, 217-238.

(27) Gundabala V. R.; Zimmerman W. B.; Routh A. F., Langmuir 2004 20, 8721.

(28) Mallégol, J.; Gorce, J.-P.; Dupont, O.; Jeynes, C.; McDonald, P.J.; Keddie, J.L. Langmuir 2002 18, 4478-4487.

(29) Charmeau, J.Y.; Gerin, P.A.; Vovelle, L.; Schirrer, R.; Holl, Y. J. Adhes. Sci. Technol. 1999, 13, 203-215.

(30) Gerin, P.A.; Grohens, Y.; Schirrer, R.; Holl, Y. J. Adhes. Sci. Technol. 1999, 13, 217-236.

(31) Tobing, S.D.; Klein, A. J. Appl. Polym. Sci. 2001, 79, 2230-2244.

(32) Ouzineb, K. Aqueous Polymer Dispersion and Process, 2008, International Patent Number WO 2008/043716 A1.

(33) Antonietti, M.; Landfester, K. Prog. Polym. Sci. 2002, 27, 689-757. 
(34) Asua, J.M. Prog. Polym. Sci. 2002, 27, 1283-1346.

(35) Anczykowski, B.; Gotsmann, B.; Fuchs, H.; Cleveland, J.P.; Elings, V.B. Appl. Surf. Sci. 1999, 140, 376.

(36) Scott W.W.; Bhushan, B. Ultramicroscopy 2003, 97, 151.

(37) Mallégol, J.; Dupont, O.; Keddie, J.L. Langmuir 2001, 17, 7022-7031.

(38) Lei, C.; Ouzineb, K.; Dupont, O.; Keddie, J.L. J. Coll. Interf. Sci. 2007, 307, 56-

63.

(39) Benmouna, F.; Dimitrova T.D.; Johannsmann, D. Langmuir 2003, 19, 10247 10253.

(40) Brandrup, J.; Immergut, E.H.; Grulcke E.A. Polymer Handbook, 4th ed.; Wiley \& Sons: New-York, 1999.

(41) Burnham, N.A.; Colton, R.J. In Scanning Probe Microscopy and Spectroscopy: Theory, Techniques, and Applications, $2^{\text {nd }}$. Bonnell D., Ed., Wiley-VCH: New York, 2001; Ch. 10, p. 337.

(42 ) Akhremitchev, B. B.; Walker, G. C. Langmuir 1999, 15, 5630-5634.

(43) Sneddon, I.N. Int. J. Eng. Sci. 1965, 3, 47-57.

(44) Wang, T.; Canetta, E.; Weerakkody, T.G.; Keddie, J.L. ACS Appl. Mater. Interf. 2009, 1, 631-639.

(45) Lakrout, H.; Sergot, P.; Creton, C. J. Adhes. 1999, 69, 307-359.

(46) Chiche, A.; Pareige, P.; Creton, C. C.R. Acad. Sci. Paris, IV 2000, 1, 1197-1204.

(47) Persson, B. N. J.; Albohr, O.; Creton, C.; Peveri, V. J. Chem. Phys. 2004, 120, 8779-8793.

(48) Portigliatti, M.; Koutsos, V.; Hervet, H.; Léger, L. Langmuir 2000, 16, 63746376. 
(49) Shull, K. R.; Creton, C. J. Polym. Sci. B Polym. Phys. 2004, 42, 4023-4043.

(50) Poivet, S.; Nallet, F.; Gay, C.; Teisseire, J.; Fabre, P. Eur. Phys. J. E 2004, 15, 97-116.

(51) Nase, J. ; Lindner, A. ; Creton, C. Phys. Rev. Lett. 2008, 101, 074503.

(52) Carelli, C.; Déplace, F.; Boissonnet, L.; Creton, C. J. Adhes. 2007, 83, 491-505.

(53) Wang, T.; Lei, C. H.; Dalton, A. B.; Creton, C.; Lin, Y.; Fernando, K. A. S.;

Sun, Y.-P.; Manea, M.; Asua, J. M.; Keddie, J. L. Adv. Mater. 2006, 18, 2730-2734. 